\title{
The Kinetics of Gold(III) Extraction by Pyridine2azopdimethylaniline in Water and in Micellar Systems
}

\author{
Sabriye Aydinoglw', Tarita Biver, Fernando Secco*, Marcella Venturini
}

Dipartimento di Chimica e Chimica Industriale, Università di Pisa - Via G. Moruzzi, 3 56124 - Pisa (Italy)

E- mails: saydinoglu@cu.edu.tr (S. Aydinoglu); tarita.biver@unipi.it (T. Biver);

fernando.secco@unipi.it (F. Secco); marcella.venturini@dcci.unipi.it (M. Venturini)

*Corresponding Author: Fernando Secco, Dipartimento di Chimica e Chimica Industriale,

Università di Pisa - Via Moruzzi, 3 - 56124 - Pisa (Italy), fernando.secco@ unipi.it, +

390502219259

\begin{abstract}
The kinetics of reaction between $\mathrm{AuCl}_{4}{ }^{-}$, and the azo-dye pyridine-2-azo-pdimethylaniline (PADA) have been investigated in water and in the presence of DTAC micelles, using classical spectrophotometry and the stopped-flow technique. PADA reacts with different chloro/hydroxo gold(III) complexes, in turn formed as the $\mathrm{pH}$ and Cl- concentration were changed, according to a network of parallel paths. In aqueous solution, at low $\mathrm{pH}$ values, a fast step is observed which is ascribed to the ligand induced expulsion of a labile water molecule from the reacting species $\mathrm{Au}\left(\mathrm{H}_{2} \mathrm{O}\right) \mathrm{Cl}_{3}$ which forms at low $\mathrm{pH}$ values. At higher values of $\mathrm{pH}$, the reaction is much slower because in the key step PADA has to replace the more inert $\mathrm{Cl}^{-}$ions in the gold coordination shell. In the presence of DTAC a remarkable catalytic effect is observed, owing to the absorption and attraction of the reactants on the micelle surface. Moreover, DTAC favors the formation of aquochloro aurates, thus inducing a change in the gold(III) speciation compared to that in water. The analysis of the data suggests that the aquo species $\mathrm{Au}\left(\mathrm{H}_{2} \mathrm{O}\right) \mathrm{Cl}_{3}$ and $\mathrm{Au}\left(\mathrm{H}_{2} \mathrm{O}\right)_{2} \mathrm{Cl}_{2}{ }^{+}$play a major role in the reaction mechanism.
\end{abstract}

1 Present Address: Department of Analytical Chemistry, Faculty of Pharmacy, Cukurova University, 01330 Adana, Turkey

KEYWORDS: DTAC, Au(III)-PADA complex, micellar catalysis, reaction mechanism, gold speciation 


\section{Introduction}

It has been observed since long time that the addition of micelles to media containing reacting systems strongly affects the kinetics and the equilibria of the reactions involved. In the presence of micelles a reaction can occur simultaneously in the micellar region and in the bulk solution and, concerning reactions of molecularity higher than one, rate acceleration occurs when the reaction partners are preferentially located in micellar pseudophase. Actually, the localization of the reacting species in the relatively small volume of the micelles leads to a large increase in the effective concentration and the reaction rate increases accordingly [1]. On the other hand, a rate decrease follows if only one the reactants has been incorporated into the micelles [2]. Acceleration (or deceleration) of reaction rates by about a 10-100 fold have been observed [3-9].

Metal ions lack the hydrophobic properties that characterize many organic ligands; therefore, they can be concentrated on the surface of micelles only if these bear a charge of opposite sign, grace to the electrostatic attraction. It follows that the metal charge and the surface charge play a crucial role in modifying the kinetics and the equilibria of reactions involving metal ions. Most of the studies on this subject have been carried out using metal ions in the aquo-form and hydrophobic ligands; the latter are entrapped in the hydrophobic core of the micelle while the former are adsorbed on the micelle surface provided that this is negatively charged [9, 10]. Less investigated are the reactions of ligand exchange where the metal is initially present in form of a complex eventually negatively charged.

The bidentate azo-dye PADA has proven to be an excellent metal extractor, being able to transfer metal ions from water to micellar phases with yields approaching $100 \%$ [11]. However, in order to optimize the conditions of the extraction process it is very important to know the kinetic and thermodynamic features of the reaction of metal binding to the extractor in the aqueous and in the micellar phase. Hence, in the framework of our studies on complex formation reactions in micellar media [3-7] we have performed a kinetic study of the reaction between $\mathrm{AuCl}_{4}^{-}$and PADA, in water and in the presence of dodecyltrimethylammonium chloride (DTAC). This surfactant has been chosen because it has been employed in a previous study of the effect of 
micelles on the $\mathrm{pK}_{\mathrm{AS}}$ of PADA. The structure of PADA is shown in Figure 1. Different from most of the studies of this kind, the metal containing species is negatively charged; hence, acceleration of the complex formation process is expected to be induced by the positively charged DTAC micelles.

Concerning the position of the protons in the structure represented in Figure 1, it should be noted that the $-\mathrm{N}=\mathrm{N}-$ group stays unprotonated whereas, in the case of dimethylamino azobenzene (indicator methyl yellow), this group is protonated at about $\mathrm{pH} 3$ [12]. However, we favour the structure of Figure 1 on the basis of a previous contribution from our laboratory [13] where the effects of DTAC on the $\mathrm{pK}_{\mathrm{A}} \mathrm{s}$ of PADA have been investigated. Our conclusions are corroborated by the results of Klotz et. al. [12] who have found that the relative basicities of competing proton acceptors lie in the order $\mathrm{O}^{-}>$pyridine $\mathrm{N}\left(\mathrm{CH}_{3}\right)_{2} \mathrm{~N}>\mathrm{N}=\mathrm{N}$.

\section{Experimental}

2.1 Materials. All the chemicals not expressly cited are of analytical grade and were employed without further purification. Chloroauric acid, $\mathrm{HAuCl}_{4} \bullet 3 \mathrm{H}_{2} \mathrm{O}$, the complexing ligand, pyridine-2-azo-p-dimethylaniline (PADA) and the surfactant dodecyltrimethylammonium chloride (DTAC) were obtained from Sigma-Aldrich. The stock solutions of these reactants were prepared by dissolving appropriate amounts of the relevant solid material in water. The gold content was determined by direct UV absorption spectrometry exploiting the absorption band of $\mathrm{AuCl}_{4}^{-}$ion centred at 233 $\mathrm{nm}$ whose maximum absorption is proportional to the gold concentration (Figure 1S of the Supporting Information). Water, purified by pumping demineralized water through a Milli-Q apparatus, was used to prepare the solutions and also as the reaction medium.

2.2 Methods. pH measurements were made using a Metrohm 713 pH-meter equipped with a combined glass microelectrode.

The spectra of PADA and of its complex with Au(III) were recorded using a Shimadzu 2450 double-beam spectrophotometer in quartz cells $(1 \mathrm{~cm}$ path length) thermostatted to within $\pm 0.1^{\circ} \mathrm{C}$.

The reaction between gold(III) and PADA displays both slow and fast kinetic effects. The slow effects were investigated using a Perkin-Elmer lambda 35 double-beam 
spectrophotometer in quartz cells $\left(1 \mathrm{~cm}\right.$ path length) thermostatted to within $\pm 0.1^{\circ} \mathrm{C}$. The reaction was started by adding a known excess of $\mathrm{HAuCl}_{4}$ to a known volume of PADA already contained in the spectrophotometric cell at prefixed values of acidity and ionic strength. The fast processes were investigated using the stopped-flow method. The apparatus, assembled in our laboratory, uses a Hi-Tech SHU-61SX2 stopped-flow sample handling unit with a mixing time of about $1 \mathrm{~ms}$. The reactant solutions were mixed and the absorbance change associated to the reaction course was monitored spectrophotometrically. Most of the experiments have been carried out at $633 \mathrm{~nm}$ because grace to the use of a red laser diode, the signal to noise ratio was much more favourable than that provided by conventional tungsten lamps [14]. Each experiment was repeated at least five times. The kinetic traces were stored in a Tektronix 2210 digital oscilloscope and then transferred to a personal computer for the mathematical analysis. The data points were processed according to single or double exponential functions using a non-linear least square program of the Jandel Scientific package (AISN software, Richmond, CA). The temperature was kept to $250.1^{\circ} \mathrm{C}$ by means of a thermostatic bath. All kinetic experiments were done under pseudo firstorder conditions, keeping the metal ion concentration, $\mathrm{C}_{\mathrm{Au}}$, at least ten times higher than that of the ligand, $\mathrm{C}_{\mathrm{L}}\left(\mathrm{C}_{\mathrm{Au}} 10 \mathrm{C}_{\mathrm{L}}\right)$, and both solutions where brought to the same acidity and ionic strength levels before mixing. Experiments in the presence of micelles were performed by mixing solutions of metal and ligand, containing the same surfactant concentration. A slow kinetic effect due to a redox process was observed, but being much slower than the substitution reaction it was disregarded.

\section{Results and discussion}

The interaction of $\mathrm{Au}(\mathrm{III})$ and PADA induces wide spectral changes both in water and in DTAC solution, as shown in Figure 2, in which the spectra of the system recorded during titrations of PADA with $\mathrm{AuCl}_{4}-$ ions are reported. The reaction under study is a ligand exchange process which, in its simplest form, can be represented by reaction (1)

$$
\mathrm{ML}^{\prime}+\mathrm{L}=\mathrm{ML}+\mathrm{L}{ }^{\prime}
$$

If the concentration of chloride ion ( $\left.\mathrm{L}^{\prime}\right)$ is in excess with respect to that of PADA (L) 
and the $\mathrm{pH}$ of the medium is kept constant, equation (1) is reduced to the apparent reaction (2).

$\mathrm{M}+\mathrm{L}=\mathrm{ML}$

The absorbance of the system changes on titrating PADA (L) with $\mathrm{AuCl}_{4}^{-}$(M) so that the titration curve exhibits two linear branches (Figure $2 \mathrm{~S}$ ), intersecting at $\mathrm{C}_{\mathrm{Au}} / \mathrm{C}_{\mathrm{L}}=1$. This reveals that, under the conditions of the experiments, the stoichiometry of the reaction is 1:1 and the complex formed (ML) contains one gold atom and one PADA molecule. The stoichiometry deduced by the experiment of Figure $2 \mathrm{~S}$ is also confirmed by the kinetic behaviour described below.

\subsection{The reaction between $A u(I I I)$ and $P A D A$ in water}

3.1.1 Reaction at $\mathrm{pH} \leq 6$. The reaction between gold(III) and PADA, in the $\mathrm{pH}$ range between 4.0 and 6.0 is sufficiently slow to be investigated using the classical spectrophotometric method. Experiments carried out varying the metal concentration under pseudo first-order conditions $\left(\mathrm{C}_{\mathrm{Au}}>10 \mathrm{C}_{\mathrm{L}}\right)$ show that the absorbance vs time curves are mono-exponential (Figure $3 \mathrm{~A}$ ). The time constant, $1 / \tau$, depends linearly on $\mathrm{C}_{\mathrm{Au}}$ (Figure 3B) according to the relationship (3)

$\frac{1}{\tau}=k_{f} C_{A u}+k_{d}$

where $\mathrm{k}_{\mathrm{f}}$ and $\mathrm{k}_{\mathrm{d}}$ are the apparent rate constants for the forward and reverse process represented by reaction (2).

The perfect agreement bewteen the experimental trace and the calculated line (Figure 3A) shows that the reaction is first-order with respect to ligand. Moreover, the linearity of the plot of Figure 3B reveals that the reaction is first-order in metal ion. In addition, the intercept value, corresponding to $\mathrm{k}_{\mathrm{d}}$, is almost zero, thus indicating that, under the employed experimental conditions, the formation of the Au(III)/PADA complex is quantitative.

The effect of chloride ion concentration and $\mathrm{pH}$ on the slow kinetic step displayed by the $\mathrm{Au}(\mathrm{III})-\mathrm{PADA}$ system has been investigated and a summary of the kinetic data 
obtained is reported in Table 1. The influence of the $\mathrm{pH}$ on the kinetics of the reaction reveals that the value of $\mathrm{k}_{\mathrm{f}}$ is relatively high and almost constant at low values of $\left[\mathrm{OH}^{-}\right]$, while it decreases as the $\left[\mathrm{OH}^{-}\right]$values are raised. The results also show that, at the lowest $\mathrm{pH}$ values, the rate is almost independent on the chloride ion content, whereas at the highest $\mathrm{pH}$ values the rate tends to increase with the chloride ion concentration. The effects of chloride and hydrogen ion concentrations on the time course of the reaction indicate that, under the conditions of the experiments, more than a single gold species takes part, directly or indirectly, in the binding process. Based on this observation, the behavior of the system can be rationalized according to the twostep process shown in Scheme 1.

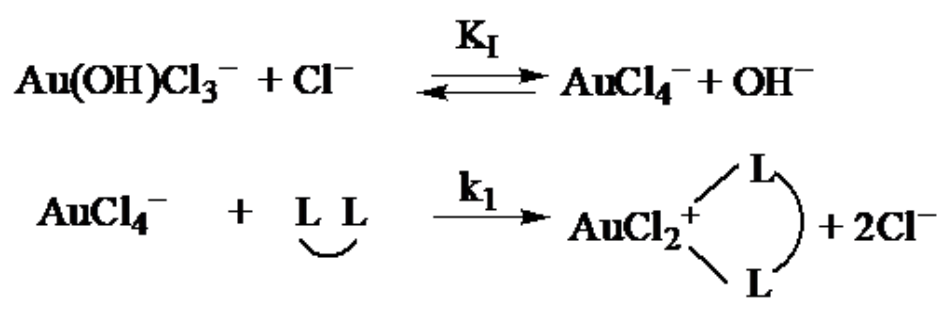

\section{Scheme 1}

PADA is here denoted as L-L to point out that both the pyridine- and the azo-nitrogen of PADA bind to $\mathrm{Au}(\mathrm{III})$ forming a chelate as the final product. The reaction scheme leads to the rate equation (4). Note that the contribution of the reverse step does not appear in equation (4) since the reaction undergoes completeness.

$$
\frac{1}{\tau_{1}}=\frac{\mathrm{K}_{\mathrm{I}_{1}}\left[\mathrm{Cl}^{-}\right] \mathrm{C}_{\mathrm{Au}}}{\mathrm{K}_{\mathrm{I}}\left[\mathrm{Cl}^{-}\right]+\left[\mathrm{OH}^{-}\right]}
$$

Comparison of equation (4) with equation (3) yields $\mathrm{k}_{\mathrm{f}}=\mathrm{K}_{\mathrm{I}} \mathrm{k}_{1}\left[\mathrm{Cl}^{-}\right] /\left(\mathrm{K}_{\mathrm{I}}\left[\mathrm{Cl}^{-}\right]+\left[\mathrm{OH}^{-}\right]\right)$and $\mathrm{k}_{\mathrm{d}}=0$. Equation (4) indicates that, for $\mathrm{K}_{\mathrm{I}}[\mathrm{Cl}]>[\mathrm{OH}]$, the values of $1 / \tau_{1}\left(\right.$ or $\mathrm{k}_{\mathrm{f}}$ ) tend to be independent of the chloride concentration, as shown in Table 1 for $\mathrm{pH}$ values less than 5.0. On the other hand, for $\mathrm{K}_{\mathrm{I}}[\mathrm{Cl}]<[\mathrm{OH}]$, the values of $1 / \tau_{1}$ tend to increase with 
[Cl]. The array of data of Table 1 has been analysed according to equation (4) and the obtained reaction parameters are $\mathrm{k}_{1}=633 \pm 49 \mathrm{M}^{1} \mathrm{~s}^{1}$ and $\mathrm{K}_{\mathrm{I}}=(3.3 \pm 1.1) \times 10^{8}$. The graphic representation of the experimental data and the calculated surface is shown in Figure $3 \mathrm{~S}$. The value of $\mathrm{K}_{\mathrm{I}}$ obtained from kinetics agrees with the value of $1.3 \times 10^{8} \mathrm{M}$ derived from equilibrium measurements by Baes and Mesmer [15]. This finding validates the proposed reaction scheme and demonstrates the usefulness of the kinetic method for the analysis of equilibria in solution. A last observation can be made on the variation of $\mathrm{k}_{\mathrm{f}}$ with $\mathrm{pH}$ (Table 1), in particular the values of $\mathrm{k}_{\mathrm{f}}$ at $\mathrm{pH}=4.0$ are lower than expected on the basis of the trend at higher $\mathrm{pH}$ values. This finding could be related to the fact that, being $\mathrm{pK}_{\mathrm{A} 2}$ of PADA equal to about 4 , the mono-protonated species HL- $\mathrm{L}^{+}$is formed in noticeable amounts at expenses of the deprotonated reactive species L-L. Under these circumstances the reaction rate is reduced.

3.1.2 Reaction at $\mathrm{pH}>6$. When the $\mathrm{pH}$ of the medium is brought to values higher than 6 , the reaction becomes suddenly much faster (Figure 4A), so that it was necessary to resort to the stopped-flow method. Note that the signal noise is rather large compared to that of the signals displayed at $\mathrm{pH}<6$ owing to the fact that the amplitude of this faster process is very small. Moreover, the signal-to-noise ratio is made unfavourable also because recording fast transients requires a short instrumental rise-time, so that the signal can be only partially smoothed.

The reciprocal relaxation time, $1 / \tau_{2}$, has been plotted as a function of $\mathrm{C}_{\mathrm{Au}}$ (Figure $4 \mathrm{~B}$ ). The linear behaviour observed, indicates that the reaction in the forward direction involves one molecule of gold(III). The positive value of the intercept reveals that in this case the binding process does not go to completion. Actually, the intercept value provides a measure of the contribution of the reverse step to the overall kinetic process. The rapidity of the reaction, being three orders of magnitude faster than that at $\mathrm{pH}<6$, and the existence of a reverse step, suggest a change of the species participating in the binding process, This suggestion is supported by the rate dependence on $\left[\mathrm{Cl}^{-}\right]$and $\mathrm{pH}$. Actually, the reaction rate displays a quadratic dependence on the chloride ion concentration (Figure 5A), while it does not appear to significantly depend on hydrogen ion concentration (Figure 5B).

The results can be rationalized on the basis of the reaction Scheme 2. 


$$
\begin{aligned}
& \mathrm{Cl}^{-}+\mathrm{Au}(\mathrm{OH})_{3} \mathrm{Cl}^{-} \stackrel{\mathrm{K}_{\mathrm{II}}}{\rightleftarrows} \mathrm{Au}(\mathrm{OH})_{2} \mathrm{Cl}_{2}{ }^{-}+\mathrm{OH}^{-}
\end{aligned}
$$

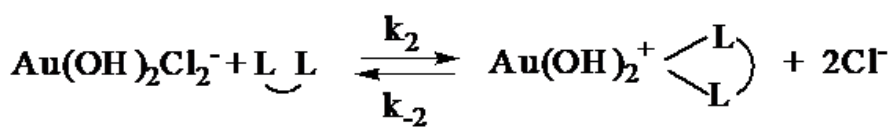

\section{Scheme 2}

According to Scheme 2, the time constant of the fast process, $1 / \tau_{2}$, is given by equation (5). For $\mathrm{K}_{\mathrm{II}}[\mathrm{Cl}]>>[\mathrm{OH}]$ the first term of equation (5) becomes a constant independent of $\left[\mathrm{Cl}^{-}\right]$and $\left[\mathrm{OH}^{-}\right]$. The statistical analysis of the data (Figure 4S) provides $\mathrm{k}_{2}=(5.7 \pm 0.6) \times 10^{5} \mathrm{M}^{-1} \mathrm{~s}^{-1}, \mathrm{k}_{-2}=(1.1 \pm 0.1) \times 10^{3} \mathrm{M}^{-2} \mathrm{~s}^{-1}$ and $\mathrm{K}_{2}=\mathrm{k}_{2} / \mathrm{k}_{-2}=$ $(5 \pm 1) \times 10^{2} \mathrm{M}$.

$\frac{1}{\tau_{2}}=\frac{\mathrm{k}_{2} \mathrm{~K}_{\mathrm{II}^{\mathrm{Au}}}\left[\mathrm{Cl}^{-}\right]}{\mathrm{K}_{\mathrm{II}}\left[\mathrm{Cl}^{-}\right]+\left[\mathrm{OH}^{-}\right]}+\mathrm{k}_{-2}\left[\mathrm{Cl}^{-}\right]^{2}$

\subsection{The reaction between $A u(I I I)$ and PADA in DTAC}

The kinetic behaviour of the gold(III)-PADA system in DTAC was investigated with the same procedure used for the study in water. The surfactant concentration was always above the DTAC cmc [16]. The occurrence of the exchange reaction in DTAC is demonstrated by the spectral variations shown in Figure 2B. The experimental conditions are the same as in water, so that the reacting system can be represented by the apparent reaction (2), allowing equation (3) to be applied. Two distinct kinetic effects are observed in this case too.

3.2.1 Reaction at $p H \leq 6$. A typical monoexponential kinetic curve, recorded in DTAC, is given in Figure 6A. The linear dependence of the reciprocal time constant on metal ion concentration (Figure 6B) indicates that the reaction is first-order in gold and 
the positive intercept reveals that, contrary to the behavior observed in water under conditions apparently similar, the reverse step of complex dissociation cannot be neglected.

The dependence of $1 / \tau_{3}$ on the chloride ion concentration has been investigated for different values of the gold (III) concentration and the graphical representation of the data, shown in Figure 5S, indicates that the binding mode is not a simple one. More detailed information is provided by the analysis of the values of $\mathrm{k}_{\mathrm{f}}$ and $\mathrm{k}_{\mathrm{d}}$ (defined as in equation (3)) measured at different $\mathrm{NaCl}$ concentrations. The results reported in Table 2 show that, in the presence of DTAC, the contribution of the reverse reaction is important, contrary to the behaviour observed in water.

Table 2 also shows that the value of $k_{d}$ displays a well-defined increase as the chloride level is raised, indicating that the back reaction becomes more and more important, as shown by the last column of Table 2 where the relative contribution of the reverse step to $1 / \tau_{3}$ is reported. This finding confirms that in the presence of DTAC the reaction is not quantitative, in agreement with the positive values of the intercepts of the plots of Figure 6B. The trends displayed by $\mathrm{k}_{\mathrm{f}}$ and $\mathrm{k}_{\mathrm{d}}$ are shown in a graphical representation in Figures 7A and B, respectively.

Table 3 reports the values of $\mathrm{k}_{\mathrm{f}}$ and $\mathrm{k}_{\mathrm{d}}$ obtained at different $\mathrm{pH}$ values. Both rate constants decrease as the $\left[\mathrm{OH}^{-}\right]$level is raised.

Concerning the reaction scheme in DTAC at $4<\mathrm{pH}<6$, it has to be noted that the $\mathrm{pH}$ on the micelle surface is higher than that of the aqueous phase [17]. Under these circumstances one could expect that hydroxylated species, as $\mathrm{Au}(\mathrm{OH}) \mathrm{Cl}_{3}{ }^{-}$could form on the micelle pseudophase [15]. Among the various reaction schemes tested the one that best represents the kinetic behaviour is Scheme 3 . 


$$
\begin{aligned}
& \mathrm{AuCl}_{4}^{-} \\
& \mathrm{K}_{\mathrm{III}} \uparrow+\mathrm{Cl}^{-} \\
& \left.\mathrm{Au}\left(\mathrm{H}_{2} \mathrm{O}\right) \mathrm{Cl}_{3}+\mathrm{LL}_{-}^{\mathrm{L}} \stackrel{\mathrm{k}_{3}}{\underset{\mathrm{k}_{-3}}{\rightleftharpoons}} \mathrm{AuCl}_{2}^{+} \succ_{\mathrm{L}}^{+\mathrm{L}}\right)+\mathrm{Cl}^{-}+\mathrm{H}_{2} \mathrm{O} \\
& \mathrm{K}_{\mathrm{IV}} \uparrow+\mathrm{OH},-\mathrm{H}_{2} \mathrm{O} \\
& \mathrm{Au}(\mathrm{OH}) \mathrm{Cl}_{3}^{-} \\
& \mathrm{K}_{\mathrm{V}} \mid \|_{\gamma}+\mathrm{OH},-\mathrm{Cl}^{-} \\
& \operatorname{AuCl}\left({ }_{\mathrm{OH}^{+}}^{\mathrm{L}}\right)
\end{aligned}
$$

\section{Scheme 3}

where the vertical reactions are fast. The relationship showing the dependence of $1 / \tau_{3}$ on the reactant concentrations has been derived in the Supporting Information and is given by equation (6).

$1 / \tau_{3}=\left\{\mathrm{k}_{3} /\left(1+\mathrm{K}_{\mathrm{III}}[\mathrm{Cl}]+\mathrm{K}_{\mathrm{IV}}[\mathrm{OH}]\right)\right\} \mathrm{C}_{\mathrm{Au}}+\left\{\mathrm{k}_{-3} \mathrm{~K}_{\mathrm{V}}[\mathrm{Cl}]^{2} /\left(\mathrm{K}_{\mathrm{V}}[\mathrm{Cl}]+[\mathrm{OH}]\right)\right\}$

Equation (6) explains the linear dependence of $1 / \tau_{3}$ on $\mathrm{C}_{\mathrm{Au}}$ and the complex dependence of $\mathrm{k}_{\mathrm{f}}$ and $\mathrm{k}_{\mathrm{d}}$ on the chloride concentration shown in Figure 7. The first term within braces of equation (6), corresponding to $\mathrm{k}_{\mathrm{f}}$, rationalizes the descending trend of $\mathrm{k}_{\mathrm{f}}$ as $[\mathrm{Cl}]$ or $\left[\mathrm{OH}^{-}\right]$do increase (Figure 7A and Table 3). On the other hand, for $\mathrm{K}_{\mathrm{v}}\left[\mathrm{Cl}^{-}\right]<\left[\mathrm{OH}^{-}\right]$, the second term within braces, corresponding to $\mathrm{k}_{\mathrm{d}}$, should increase more than linearly as $[\mathrm{Cl}]$ is increased (as shown in Figure 7B) and should decrease on rising the $[\mathrm{OH}]$ level (as shown in Table 3). Note that, among the various reaction schemes tested, only the Scheme 3 explains the observed dependence of $\mathrm{k}_{\mathrm{f}}$ on $\left[\mathrm{Cl}^{-}\right]$and $[\mathrm{OH}]$. The analysis of the data provides $\mathrm{K}_{\mathrm{III}} / \mathrm{k}_{3}=0.28 \pm 0.03 \mathrm{~s}$, $\left(1+10^{-8} \mathrm{~K}_{\mathrm{IV}}\right) / \mathrm{k}_{3}=(1.2 \pm 0.1) \times 10^{-2} \mathrm{M} \mathrm{s}, \mathrm{k}_{-3}=(2.2 \pm 0.3) \times 10^{-2} \mathrm{M}^{-2} \mathrm{~s}^{-1}$ and $\mathrm{K}_{\mathrm{V}}=(5.0$ $\pm 0.3) \times 10^{-8}$.

DTAC is expected to exert a catalytic effect on the binding reaction because the gold 
containing species and PADA are both concentrated on the micelle surface (the former because of the electrostatic attraction and the latter owing to hydrophobic interactions). The values of $\mathrm{k}_{\mathrm{f}}$ and $\mathrm{k}_{\mathrm{d}}$ have been determined for different surfactant concentrations and the results are reported in Figure 8.

Figure 8A shows that the maximum rate acceleration occurs just above the surfactant cmc $(0.01 \mathrm{M})$, corresponding to an increase of $\mathrm{k}_{\mathrm{f}}$ by a factor of 15.6 with respect to the value in water. The figure also shows that further increase of the surfactant concentration results in a reduction of the reaction rate. We ascribe this behaviour to a decrease of the surface potential [17] and to the increase of the concentration of sites available to the reactants which results in a dilution of the reaction partners $[11,18]$. The increase of rate shown in Figure $8 \mathrm{~B}$ for [DTAC] $>0.01$ is also due to the catalysis of the reverse step which involves the encounter in a restricted volume of the $\mathrm{Au}$ PADA complex with $\mathrm{Cl}$ ions, while the subsequent decreasing trend is to be ascribed to the above mentioned dilution effect.

3.2.2 Reaction at $\mathrm{pH} \leq 3$. At low $\mathrm{pH}$ the reaction between PADA and gold(III) becomes so fast to require the use of the stopped-flow technique. Figure 6S shows a kinetic curve in $0.02 \mathrm{M}$ DTAC. Since the amplitude of the signal at $633 \mathrm{~nm}$ was too small, the curves were recorded at $475 \mathrm{~nm}$ where the signal-to-noise ratio was definitely more favourable. The reaction is first-order with respect to gold(III), as shown in Figure 9A and, in this case too, an equilibrium situation is reached, as revealed by the positive intercept of the plot. It should be noted, however, that for $\mathrm{pH}$ $<3$ the reaction is more than 1000-fold faster compared to the reaction investigated at $\mathrm{pH}>4$. A so sudden change suggests that a new gold containing species should react with PADA. The parameter $1 / \tau_{4}$ decreases on increasing $\left[\mathrm{Cl}^{-}\right]$and no sign of rate enhancement could be observed even at the highest values of $\left[\mathrm{Cl}^{-}\right]$(Figure 9B), contrary to the behaviour exhibited by the reacting system in the range of $\mathrm{pH}$ between 4 and 6 , where a remarkable increase of $1 / \tau_{3}$ is displayed for $\left[\mathrm{Cl}^{-}\right]>0.15 \mathrm{M}$ (Figure 5S). This result reveals that at low $\mathrm{pH}$ values chloride ions are not involved in the reverse process. On this basis, reaction paths involving of the species $\mathrm{AuCl}_{4}{ }^{-}, \mathrm{Au}(\mathrm{OH})$ $\mathrm{Cl}_{3}{ }^{-}, \mathrm{Au}\left(\mathrm{H}_{2} \mathrm{O}\right) \mathrm{Cl}_{3}$ or $\mathrm{Au}(\mathrm{OH})_{2} \mathrm{Cl}_{2}^{-}$should be ruled out since these would involve a reverse step dependent on the chloride ion concentration (see the schemes above). The only species that matches the requirements dictated by the kinetic behaviour is $\mathrm{Au}\left(\mathrm{H}_{2} \mathrm{O}\right)_{2} \mathrm{Cl}_{2}{ }^{2+}$. 
The reaction rate depends on the hydrogen ion concentration (Figure 7S) but the dependence (which will be rationalized below) is too limited (when compared to that observed in the $\mathrm{pH}$ range between 4 and 6) to suggest the involvement of protons (or $\mathrm{OH}^{-}$ions) in the substitution process. Hence, this finding as well concurs in ruling out any contribution from oxydrylated species. This conclusion is also supported by the fact that, at $\mathrm{pH}<3$, the oxydrylated forms of $\mathrm{Au}(\mathrm{III})$ are absent in water [15] and are likely minority in the presence of DTAC. Note that in the conditions here employed $(\mathrm{pH}<3$ and $[\mathrm{DTAC}]=0.02 \mathrm{M})$ the dye is mainly present in the monoprotonated (HL$\mathrm{L}^{+}$) and diprotonated (HL-LH ${ }^{2+}$ ) forms [14]. Metal binding to $\mathrm{HL}-\mathrm{LH}^{2+}$ is hindered due to protonation of the pyridine site; hence, the form $\mathrm{HL}-\mathrm{L}^{+}$is presumably the reactive one. If this is true, a plot of $1 / \tau_{4}$ vs. $\alpha_{\mathrm{HLL}}$ (where $\alpha_{\mathrm{HLL}}$ is the molar fraction of $\mathrm{HLL}^{+}$) should be linear (Figure 9C), as experimentally found. On the basis of the obtained results, the reaction scheme which rationalizes the features of the PADA binding to gold (III) at $\mathrm{pH}<3$ is represented by Scheme 4 (the proton in the HL- $\mathrm{L}^{+}$species is not involved the chelation process, being bound to the $-\mathrm{N}\left(\mathrm{CH}_{3}\right)_{2}$ residue of PADA)

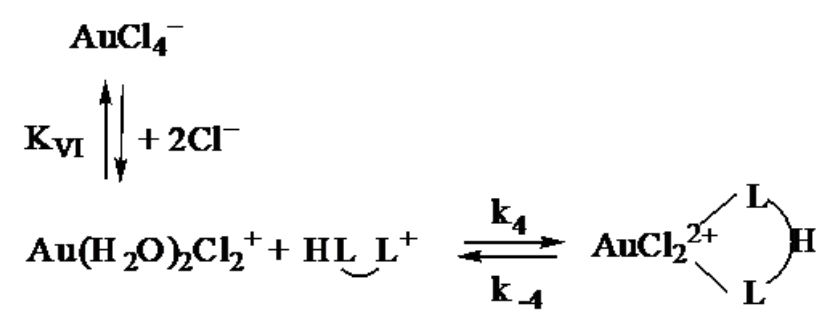

\section{Scheme 4}

The expression for the time constant derived according to Scheme 4 (Supporting Information) is represented by equation (7).

$\frac{1}{\tau_{4}}=\frac{\mathrm{k}_{4} \mathrm{C}_{\mathrm{Au}} \alpha_{\mathrm{HLL}}}{1+\mathrm{K}_{\mathrm{VI}}\left[\mathrm{Cl}^{-}\right]^{2}}+\mathrm{k}_{-4}$

The analysis of the data provides $\mathrm{k}_{4}=(2 \pm 1) \times 10^{5} \mathrm{M}^{-1} \mathrm{~s}^{-1}, \mathrm{k}_{-4}=140 \pm 20 \mathrm{~s}^{-1}, \mathrm{~K}_{\mathrm{VI}}=$ 
$60 \pm 30 \mathrm{M}^{-2}$ and $\mathrm{K}_{4}=\mathrm{k}_{4} / \mathrm{k}_{-4}=(1.4 \pm 0.9) \times 10^{3} \mathrm{M}^{-1}$

4. Conclusions The reaction between tetrachloro aurate and PADA occurs through various paths involving different species of $\mathrm{Au}(\mathrm{III})$ both in water and in DTAC. The extent of the contribution of each path to the ligand substitution process depends on the $\mathrm{pH}$ and chloride content of the solution. Between $\mathrm{pH} 4$ and 6 , in water, the substitution process is quantitative, whereas in the presence of DTAC micelles an equilibrium situation is reached. The different behaviour is to be ascribed to the fact that the reactants (free PADA and Au chloro-hydroxocomplexes) display a stronger tendency to be adsorbed/attracted on the positively charged micelle surface, compared to the products (positively charged Au-PADA complexes). Interestingly, the species $\mathrm{AuCl}_{3}$ (or $\mathrm{Au}\left(\mathrm{H}_{2} \mathrm{O}\right) \mathrm{Cl}_{3}$ and $\mathrm{Au}(\mathrm{OH})_{2} \mathrm{Cl}_{2}{ }^{+}$which are absent in aqueous solution, seems to be present in remarkable concentrations in DTAC where it plays a dominant role in the kinetics of the $\mathrm{Au} / \mathrm{PADA}$ system. The presence of $\mathrm{AuCl}_{3}$ could be justified with the hypothesis that the positive sites of the DTAC micelles do exert an attraction on the chloride atoms of the $\mathrm{AuCl}_{4}^{-}$which results in a weakening of the $\mathrm{Au}-\mathrm{Cl}$ bond. The enhanced reactivity of $\mathrm{Au}\left(\mathrm{H}_{2} \mathrm{O}\right) \mathrm{Cl}_{3}$ stems from the lability of the water molecule which is rapidly replaced by the first chelating arm of PADA. In the limit, it could happen that, owing to the hydrophobic character of the micelle, the water is easily expelled from the surface bound aquo-chloro $\mathrm{Au}(\mathrm{III})$ complexes even in the absence of ligand. The resulting dehydrated forms, being coordinatively unsaturated, should display an increased reactivity as far as complex formation reactions are concerned.

Acknowledgements The financial support by Obra Social "la Caixa", project OSLC-2012-007, and by the Ministerio de Economia y Competividad - Gobierno de España, project MINECO CTQ2014-58812-C2-2-R, are gratefully acknowledged. 


\section{REFERENCES}

[1] L.S. Romsted, Micellization, Solubilization and Microemulsions, in: K.L. Mittal (Eds.), Springer, Berlin, 1977, pp. 509-530.

[2] H.S. Kim, C. Tondre, On a Possible Role of Microemulsions for Achieving the Separation of Ni-2+ and Co-2+ from Their Mixtures on a Kinetic Basis, Separ. Sci. Technol. 24 (1989) 485-493.

[3] M.R. Beccia, T. Biver, B. Garcia, J.M. Leal, F. Secco, R. Ruiz, M. Venturini, Mechanism of $\mathrm{Ni2}+$ and $\mathrm{NiOH}+$ interaction with hydroxamic acids in SDS: evaluation of the contributions to the equilibrium and rate parameters in the aqueous and micellar phase, Dalton Trans. 41 (2012) 7372-7381.

[4] T. Biver, L. Ghezzi, V. Malvaldi, F. Secco, M.R. Tine, M. Venturini, Kinetics and Equilibria of the Interaction of 8-Hydroxyquinoline with Gallium(III) in Water and Sodium Dodecyl Sulfate Solution, J. Phys. Chem. B 113 (2009) 1598-1606.

[5] L. Ghezzi, G. Monteleone, B. Robinson, F. Secco, M.R. Tine, M. Venturini, Metal extraction in water/micelle systems: Complex formation, stripping and recovery of $\mathrm{Cd}(\mathrm{II})$, Colloids Surf. A 317 (2008) 717-721.

[6] T. Biver, A. Boggioni, F. Secco, A. Venturini, Gallium(III)/4 (2-pyridylazo)resorcinol system in water and SDS solution: Kinetics and thermodynamics, Langmuir 24 (2008) 36-42.

[7] G. Monteleone, L. Morroni, B. Robinson, M.R. Tine, M. Venturini, F. Secco, Metal ion extraction in surfactant solution: $\mathrm{Ni2}+(\mathrm{aq})$ and $\mathrm{Cd} 2+(\mathrm{aq})$ with the ligands PADA and PAR in SDS micellar systems, Colloids Surf. A 243 (2004) 23-31.

[8] P.D.I. Fletcher, B.H. Robinson, Effect of Organized Surfactant Systems on the Kinetics of Metal-Ligand Complex-Formation and Dissociation, J. Chem. Soc. Farad. Trans. 80 (1984) 2417-2437.

[9] C.A. Bunton, Micellar catalysis and inhibition, Prog. Solid State Chem. 8 (1973) 239-281.

[10] P. Pallavicini, Y.A. Diaz-Fernandez, L. Pasotti, Micelles as nanosized containers for the self-assembly of multicomponent fluorescent sensors, Coord. Chem. Rev. 253 (2009) 2226-2240.

[11] A.D. James, B.H. Robinson, Micellar catalysis of metal-complex formation - Kinetics of reaction between $\mathrm{Ni}(\mathrm{II})$ and pyridine-2-azo-p-dimethylaniline (PADA) in presence of sodium dodecylsulfate micelles - model system for study of metal-ion reactivity at charged interfaces, Journal Chemical Society Faraday Trans 74 (1978) 10-21.

[12] I.M. Klotz, H.A. Fiess, J.Y.C. Ho, M. Mellody, The position of the proton in substituted azobenzene molecules., J. Am. Chem. Soc. 76 (1954) 5136-5140.

[13] S. Aydinoglu, T. Biver, F. Secco, M. Venturini, Effects of micelle nature and concentration on the acid dissociation constants of the metal extractor PADA, Colloids Surf. A 461 (2014) 303-309.

[14] M. Citi, C. Festa, F. Secco, M. Venturini, A Spectrophotometric Apparatus with Laser Sources for Measurements of Fast Transient Signals, Instrum. Sci. Technol. 23 (1995) 191-199.

[15] C.F. Baes, R.E. Mesmer, The hydrolysis of cations, Wiley, 1976.

[16] L. Ghezzi, B.H. Robinson, F. Secco, M.R. Tine, M. Venturini, Binding of Pd(II) to Pada in water/micellar system: Complex formation, kinetics in water and DTAC solution, Colloids Surf. A 292 (2007) 139-147.

[17] G.S. Hartley, J.W. Roe, Ionic concentrations at interfaces, Transactions of the Faraday Society 35 (1940) 101-109.

[18] C.A. Bunton, Reaction-Kinetics in Aqueous Surfactant Solutions, Catal. Rev. 20 (1979) 1-56. 


\section{LEGEND TO FIGURES}

Figure 1. Molecular structure of pyridine-2-azo-p-dimethylaniline (PADA) in the fully protonated form $\left(\mathrm{HL}-\mathrm{LH}^{2+}\right)$.

Figure 2. Absorbance spectra of the $\mathrm{Au}(\mathrm{III}) / \mathrm{PADA}$ system in water (A) and in DTAC solution (B) recorded at $25{ }^{\circ} \mathrm{C}$. The less energetic band corresponds to the complex. (A) $\mathrm{C}_{\mathrm{Au}}$ from $0 \mathrm{M}$ (a) to $9.5 \times 10^{-5} \mathrm{M}$ (b), $\mathrm{C}_{\mathrm{PADA}}=3 \times 10^{-6} \mathrm{M},[\mathrm{NaCl}]=0.03 \mathrm{M}, \mathrm{pH}=$ 6.5; (B) $\mathrm{C}_{\mathrm{Au}}$ from $0 \mathrm{M}$ (a) to $3 \times 10^{-5} \mathrm{M}$ (b), $\mathrm{C}_{\mathrm{PADA}}=4 \times 10^{-6} \mathrm{M}$, [DTAC] $=0.01 \mathrm{M}, \mathrm{pH}$ $=4.2$.

Figure 3. The reaction between $\mathrm{Au}(\mathrm{III})$ and $\mathrm{PADA}$ in water at $\mathrm{pH} \leq 6$ : (A) Absorbance change at $633 \mathrm{~nm}$ showing the time course of the gold(III)-PADA complex formation; $\mathrm{C}_{\mathrm{Au}}=1.010^{4} \mathrm{M}$. The continuous line represents the trend calculated according to a monoexponential function. (B) Plot of $1 / \tau_{1}$ vs. concentration of gold(III) in the kinetic analysis of the gold(III)-PADA system; in (A) and (B) CPADA $=1.010^{5} \mathrm{M}, \mathrm{pH}=5.0,[\mathrm{NaCl}]=0.04 \mathrm{M}, \mathrm{T}=25 \mathrm{C}$.

Figure 4. The reaction between $\mathrm{Au}(\mathrm{III})$ and $\mathrm{PADA}$ in water at $\mathrm{pH}>6$ : kinetic behaviour of the Au-PADA system $([\mathrm{NaCl}]=0.03 \mathrm{M}, \mathrm{pH}=6.5, \mathrm{~T}=25 \mathrm{C}) ;(\mathrm{A})$ Stopped-flow experiment with $\mathrm{C}_{\mathrm{Au}}=5.010^{5} \mathrm{M}, \mathrm{C}_{\mathrm{PADA}}=5.010^{6} \mathrm{M}, \lambda=633 \mathrm{~nm}$. The continuous line represents the trend calculated according to a monoexponential function. (B) Dependence of the reciprocal time constant, $1 / \tau_{2}$, on gold(III) concentration.

Figure 5. Kinetic behaviour of the reaction between $\mathrm{Au}(\mathrm{III})$ and PADA in water at $\mathrm{pH}>6:\left(\mathrm{C}_{\mathrm{Au}}=5.010^{5} \mathrm{M}, \mathrm{C}_{\mathrm{PADA}}=5.010^{6} \mathrm{M}, \mathrm{T}=25 \mathrm{C}\right):(\mathrm{A})$ Dependence of $1 / \tau_{2}$ on $\left[\mathrm{Cl}^{-}\right]$at $\mathrm{pH}=6.5$; (B) dependence of $1 / \tau_{2}$ on $\left[\mathrm{H}^{+}\right]$at $[\mathrm{NaCl}]=0.03 \mathrm{M}$. The continuous lines have been calculated using equation (5).

Figure 6. Kinetic behaviour of the reaction between gold(III) and PADA in $0.02 \mathrm{M}$ DTAC at $\mathrm{pH}=6.0\left(\mathrm{C}_{\mathrm{PADA}}=5.010^{6} \mathrm{M}, \mathrm{T}=25 \mathrm{C}\right):(\mathrm{A})$ kinetic curve recorded at $\mathrm{C}_{\mathrm{Au}}=$ $5.010^{4} \mathrm{M},[\mathrm{NaCl}]=0.10 \mathrm{M},=633 \mathrm{~nm}$. The continuous line represents the trend calculated according to a monoexponential function; (B) plots of the time constant, 
$1 / 3$, vs $\mathrm{C}_{\mathrm{Au}}$ at different $\mathrm{pH}$ values, $[\mathrm{NaCl}]=0.04 \mathrm{M}$.

Figure 7. Dependence for the gold(III)-PADA system of the forward (A) and reverse (B) rate constant of the slow effect $\left(1 / \tau_{3}\right)$ on the $\mathrm{Cl}$ concentration. [DTAC] $=0.02 \mathrm{M}$, $\mathrm{pH}=6.0, \mathrm{~T}=25^{\circ} \mathrm{C}$.

Figure 8. Dependence of the apparent rate constants, $k_{f}$ and $k_{d}$, for the gold(III)PADA system on the DTAC concentration. $\mathrm{C}_{\mathrm{Au}}=5.010^{5} \div 510^{4} \mathrm{M}, \mathrm{C}_{\mathrm{PADA}}=5.010^{6} \mathrm{M}$, $\mathrm{pH}=4.2, \mathrm{~T}=25 \mathrm{C}$.

Figure 9. Plots of the reciprocal time constant, $1 / \tau_{4}$, for the fast effect of the gold(III)PADA system in $0.02 \mathrm{M}$ DTAC, $\mathrm{C}_{\mathrm{PADA}}=5.010^{6} \mathrm{M}, \mathrm{T}=25^{\circ} \mathrm{C}$. (A) vs. gold(III) concentration, $[\mathrm{NaCl}]=0.04 \mathrm{M}, \mathrm{pH}=3$; (B) vs. chloride ion concentration, $\mathrm{C}_{\mathrm{Au}}=$ $7.010^{5} \mathrm{M}, \mathrm{pH}=2.0 ;(\mathrm{C})$ vs. $\alpha_{\mathrm{HLL}}$, the molar fraction of the monoprotonated PADA, $\mathrm{C}_{\mathrm{Au}}=7.0 \times 10^{5} \mathrm{M},[\mathrm{NaCl}]=0.04 \mathrm{M}$.

Table 1. Values of the forward rate constant, $\mathrm{k}_{\mathrm{f}}$, for the slow effect of the $\mathrm{Au}(\mathrm{III})-$ PADA system in aqueous solution at different $\mathrm{Cl}$ and $\mathrm{H}^{+}$concentrations. $\mathrm{C}_{\mathrm{Au}}=5.010^{5}$ $\mathrm{M}, \mathrm{C}_{\mathrm{PADA}}=5.010^{6} \mathrm{M}, \mathrm{T}=25 \mathrm{C}$.

\begin{tabular}{ccccccc} 
& & \multicolumn{5}{c}{$\mathbf{k}_{\mathbf{f}}\left(\mathbf{M}^{-1} \mathbf{s}^{\mathbf{1}}\right)$} \\
\hline$p H$ & 4.0 & 4.5 & 5.0 & 5.5 & 6.0 \\
{$\left[\mathrm{OH}^{-}\right](\mathrm{M})$} & & $1.0 \times 10^{-10}$ & $3.2 \times 10^{-10}$ & $1.0 \times 10^{-9}$ & $3.2 \times 10^{-9}$ & $1.0 \times 10^{-8}$ \\
\hline $\begin{array}{c}n \\
{[\mathbf{N a C l}]} \\
(\mathbf{M})\end{array}$ & 0.02 & 86 & 130 & 58 & 10 & 8 \\
& 0.04 & 78 & 126 & 60 & 22 & 8 \\
& 0.07 & 64 & 120 & 70 & 34 & 16 \\
& 0.10 & 58 & 118 & 82 & 34 & 14 \\
& 0.15 & 64 & 114 & 118 & 54 & 20 \\
& 0.20 & 66 & 128 & 136 & 68 & 28
\end{tabular}




\begin{tabular}{ccccccc}
\hline $\begin{array}{c}{[\mathbf{N a C l}]} \\
(\mathbf{M})\end{array}$ & 0.02 & 86 & 130 & 58 & 10 & 8 \\
& 0.04 & 78 & 126 & 60 & 22 & 8 \\
& 0.07 & 64 & 120 & 70 & 34 & 16 \\
& 0.10 & 58 & 118 & 82 & 34 & 14 \\
& 0.15 & 64 & 114 & 118 & 54 & 20 \\
& 0.20 & 66 & 128 & 136 & 68 & 28 \\
& 0.25 & 62 & 118 & 144 & 82 & 34 \\
\hline
\end{tabular}

Table 2. Dependence of $\mathrm{k}_{\mathrm{f}}$ and $\mathrm{k}_{\mathrm{d}}$ on [Cl] for the gold(III)-PADA system in $0.02 \mathrm{M}$ DTAC; $\mathrm{pH}=6.0, \mathrm{~T}=25^{\circ} \mathrm{C}$. The last column reports the relative contribution of the back reaction (\% BR) to the value of $1 / \tau_{3}$.

\begin{tabular}{l|l|l|l|l|l|}
\hline$[\mathrm{Cl}](\mathrm{M})$ & $\mathrm{k}_{\mathrm{f}}\left(\mathrm{M}^{1} \mathrm{~s}^{1}\right)$ & $10^{4} \mathrm{k}_{\mathrm{d}}\left(\mathrm{s}^{1}\right)$ & $\begin{array}{l}10^{-4} \mathrm{~K}_{\text {app }}=\mathrm{k}_{\mathrm{f}} / \mathrm{k}_{\mathrm{d}} \\
\left(\mathrm{M}^{1}\right)\end{array}$ & $\%$ \\
\cline { 2 - 6 } 0.04 & 301 & 183 & 1.70 .3 & 23 \\
\hline 0.06 & 371 & 112 & 3.40 .7 & 13 \\
0.12 \\
\cline { 2 - 6 } 0.17 & 221 & 192 & 1.20 .2 & 31 \\
0.22 \\
0.27 & 161 & 332 & 0.480 .06 & 51 \\
\hline & 141 & 551 & 0.250 .02 & 66 \\
\hline & 161 & 771 & 0.210 .02 & 71 \\
\hline
\end{tabular}

Table 3. Forward and reverse rate constants for the slow effect observed in the gold(III)-PADA system at different $\mathrm{pH}$ values in $0.02 \mathrm{M}$ DTAC. $[\mathrm{NaCl}]=0.04 \mathrm{M}, \mathrm{T}=$ $25 \mathrm{C}$. 


\begin{tabular}{lllll}
\hline $\mathrm{pH}$ & $\begin{array}{l}10^{9}\left[\mathrm{OH}^{-}\right] \\
(\mathrm{M})\end{array}$ & $\begin{array}{l}\mathrm{k}_{\mathrm{f}} \\
\left(\mathrm{M}^{-1} \mathrm{~s}^{-1}\right)\end{array}$ & $\begin{array}{l}10^{4} \mathrm{k}_{\mathrm{d}} \\
\left(\mathrm{s}^{-1}\right)\end{array}$ & $\begin{array}{l}10^{-4} \mathrm{~K}_{\mathrm{app}}=\mathrm{k}_{\mathrm{f}} / \mathrm{k}_{\mathrm{d}} \\
\left(\mathrm{M}^{1}\right)\end{array}$ \\
\hline 4.0 & 0.10 & 70020 & - & - \\
\hline 4.5 & 0.32 & 20020 & 15020 & 1.30 .3 \\
\hline 5.0 & 1.0 & 11010 & 573 & 1.90 .3 \\
\hline 5.5 & 3.2 & 602 & 236 & 2.60 .8 \\
\hline 6.0 & 10 & 371 & 112 & 3.40 .7
\end{tabular}

